\title{
BMJ Open Assessment of public oral healthcare services in Curitiba, Brazil: a cross- sectional study using the Primary Care Assessment Tool (PCATool)
}

\author{
Antonio Carlos Nascimento, ${ }^{1}$ Simone Tetü Moysés, ${ }^{2}$ Renata lani Werneck, ${ }^{2}$ \\ Marilisa Carneiro Leão Gabardo, ${ }^{1}$ Samuel Jorge Moysés ${ }^{2}$
}

To cite: Nascimento AC, Moysés ST, Werneck RI, et al. Assessment of public oral healthcare services in Curitiba, Brazil: a crosssectional study using the Primary Care Assessment Tool (PCATool). BMJ Open 2019;9:e023283. doi:10.1136/ bmjopen-2018-023283

- Prepublication history for this paper is available online. To view these files, please visit the journal online (http://dx.doi. org/10.1136/bmjopen-2018023283).

Received 29 March 2018 Revised 30 0ctober 2018 Accepted 7 December 2018

Check for updates

(C) Author(s) (or their employer(s)) 2019. Re-use permitted under CC BY-NC. No commercial re-use. See rights and permissions. Published by BMJ.

${ }^{1}$ School of Health Sciences, Universidade Positivo, Curitiba, Brazil

${ }^{2}$ School of Life Sciences,

Pontifícia Universidade Católica do Paraná, Curitiba, Brazil

Correspondence to Dr Marilisa Carneiro Leão Gabardo; marilisagabardo@gmail.com

\section{ABSTRACT}

Objectives To compare two different models of public oral health in primary care services, a so-called family health strategy (FHS), as opposed to non-FHS services designated as 'conventional' healthcare $(\mathrm{CHC})$, regarding the presence and extent of the attributes of 'good' primary healthcare (PHC). The null hypothesis of this study is that the attributes do not differ between the FHS and CHC. Design Cross-sectional.

Setting Public PHC services in Curitiba, the state capital of Paraná.

Participants PHC users of the public oral health network $(n=900)$ and dentists active in this municipal network $(n=203)$.

Primary and secondary outcome measures The Primary Care Assessment Tool (PCATool)-Dentists and PCATool-Users were used to analyse the primary outcomes ('essential' attributes) and secondary outcomes ('derived' attributes) in the PHC.

Results Overall, the primary care services in oral health were well evaluated, both by users and by dentists, with mean scores ascribed to PHC attributes mostly above the cut-off point (6.6). The exception for users were affiliation (6.36; $95 \% \mathrm{Cl} 6.11$ to 6.60$)$ and accessibility $(5.83 ; 95 \% \mathrm{Cl}$ 5.78 to 5.89); and for dentists the accessibility (5.80; $95 \% \mathrm{Cl} 5.63$ to 5.96). When comparing FHS and CHC, there was a superiority of the FHS model, which reached a general mean score of 7.53 (95\% Cl 7.48 to 7.58 ) among users and 7.56 (95\% $\mathrm{Cl} 7.45$ to 7.67$)$ among dentists; on the other hand, the $\mathrm{CHC}$ general mean score was of 6.61 (95\% Cl 6.49 to 6.73$)$ and 6.68 (95\% Cl 6.56 to 6.80$)$ respectively for users and dentists.

Conclusions The results reveal a reasonable level of attainment of PHC attributes in the services investigated. Nevertheless, public health managers should make efforts to reduce the difficulties faced by users in accessing dental care. The more positive results achieved by FHS services indicate that the provision of oral healthcare under this strategy should be expanded.

\section{INTRODUCTION}

Improving people's income and living conditions, with the consequent positive impacts on health, ${ }^{1}$ and implementing the principles

\section{Strengths and limitations of this study}

- The study uses a cross-culturally validated instrument, and we deal with the Primary Care Assessment Tool in a setting of primary care services that includes oral health; therefore, we did an innovative study applying it to dentists, as done in other studies.

- We were able to collect data from a large sample of patients with a high response rate, as well as a representative sample of dentists who work in the investigated network.

- The study compared the perspectives of patients and primary care practitioners in oral health.

- Since it is a cross-sectional study, the limitations may be related to the establishment of causal relationships.

- The tool is based on subjective self-perception reports about primary care services, rather than clinical observation, so the results should be interpreted taking this into account.

of the Alma-Ata Declaration on primary healthcare $(\mathrm{PHC})^{2}$ are objectives that many governments seek to put into practice.

However, PHC is widely misunderstood as a less important level of the health services network. Its role is viewed as providing services of low complexity with lower cost and second-rate quality. It is usual for PHC to be organised around the provision of care for poor people and individuals with supposedly minor problems. In fact, PHC should be understood as the point at which good care is first provided, where the user gains access to the entry door for the health network and health teams solves many of the most common and important health problems. ${ }^{3}$

Investment in PHC is justifiable as the findings of various studies show that there is a correlation between increased investment in PHC and improved health indicators, ${ }^{4-6}$ user satisfaction ${ }^{7}$ and financial costs that can be 
better borne by local government. ${ }^{3}$ In general, similar reasoning and expectations can also be applied to investment in PHC for oral health. This is particularly true in countries such as Brazil, where public oral health is an integral part of PHC in the National Health System. Brazil is highly complex as regards the health of its population since it crosses the epidemiological transition still with an important load of transmissible diseases, which are typical of underdeveloped societies, and a growing prevalence of chronic diseases as it happens in rich countries. ${ }^{8}$

An issue that needs to be addressed by PHC is inequality of access to oral health, as being able to see a dentist remains a major problem in many countries. ${ }^{9-12}$ In Brazil, despite advances that have been made following the introduction of the 'Sistema Único de Saúde (SUS)' (Brazilian National Health System) in $1988,{ }^{13}$ the inequalities will persist if the current model of dental practice continues. This model is predominantly based on the individual treatment of diseases with little emphasis on health promotion and disease prevention. Therefore, investigating the quality of oral health services in PHC is an important theoretical, methodological and practical endeavour.

Such is the case of Curitiba, capital of Paraná in southern Brazil, which has about 2 million inhabitants and is known throughout the country and abroad for its innovations in urban planning. Approximately $70 \%$ of the population of Curitiba uses the SUS when they need oral care. ${ }^{14}$ In the city, oral health teams operate under two different models of PHC. One, called the Family Health Strategy (FHS), was developed to improve family and patient-centred PHC by means of multiprofessional teams. Each team is responsible for monitoring around 1000 families located in a well-defined geographical area, taking into account their degree of vulnerability. The other, with teams not associated with the FHS, is known in Brazil as 'conventional' healthcare (CHC), which provide routine clinical care that is circumscribed to the biomedical paradigm and is focused on procedures for the treatment of already existing health problems.

Investigations are justifiable that make use of suitable instruments for measuring accessibility to healthcare, among other principles of PHC, ${ }^{1516}$ as their findings facilitate evaluation of the existing situation, to provide support for decision-making by municipal public sector managers. It is also important to assess the typical viewpoints of practitioners and users of health services as they elaborate distinct rationales about reality. Transparent and dialogic relationships between practitioners and users have a direct effect on increasing satisfaction with quality as well as on loyalty to services by meeting experiences that enhance public governance and mutual accountability.

An important instrument for evaluating structural and process characteristics of PHC is the Primary Care Assessment Tool (PCATool) ${ }^{17}$ which was validated for PHC services in Brazil. ${ }^{18-21}$ It allows evaluation of the presence and extent of essential and derived PHC attributes, that is, whether the actions undertaken by a health service are consistent with evidence-based and good practices recommendations for PHC. PCATool has adequate psychometric characteristics and a multidimensional structure that is valid for the identification, monitoring and evaluation of PHC attributes. ${ }^{22}$ There is a notable gap in the use of this instrument in the international literature for evaluation of oral health services in primary care, in addition to a shortage of initiatives that offer integration of public oral health and primary care services. ${ }^{23} 24$ There are even heated discussions about whether 'the perfect smile is a medical need worthy of public subsidy', that is, whether there should be integration of dentistry into public health services. ${ }^{25}$

Based on previous assumptions, the main aim of this cross-sectional study is to compare the presence and extent of PHC attributes in public oral health services in Curitiba, Brazil, using the PCATool. The null hypothesis is that the attributes do not differ between the FHS and CHC services.

\section{METHOD}

\section{Study design and sample}

This cross-sectional study was designed to investigate the multidimensional context of the provision of primary public oral health services in Curitiba. The city currently has 109 PHC units providing medical, nursing, mental health and dental services. More than 600 dentists work in these PHC units as part of multiprofessional teams providing healthcare for the population. The city also has three specialised referral centres for oral health. ${ }^{26}$ To clarify the different job arrangements of dentists, those who work in CHC units are hired on a part-time basis (4hours/day work contract) and those working in FHS units are full-time ( 8 hours/day). FHS teams also have greater institutional support, including continuous training and higher financial incentives, which seems to motivate them to develop greater links and commitment to the users for whom they are responsible.

The sample was drawn from $109(100 \%)$ primary health units with oral health teams, operating at the time of completion of the fieldwork. Sixty units (58.8\%), consisting of 30 units of the FHS stratum and 30 of the CHC stratum, were chosen using stratified random sampling. The sampling procedure was performed by the principal investigator using a name list of all units in the municipal health network, and subgroups corresponding to the two categories of interest (FHS and CHC) were numbered and randomly selected based on the Excel RAND function. Of all dentists in the municipal network, 431 provided PHC at the time of field research. The remaining 169 dentists were mainly working at the secondary level (specialised units), in managerial positions or they were on leave for health treatment or for other reasons. The response rate was $72.5 \%$ in the FHS ( $\mathrm{n}=79$ dentists) and $80.5 \%$ in the $\mathrm{CHC}(\mathrm{n}=124$ dentists), giving a total of 203 dentists.

The user sample was selected from the municipal PHC information system, which contains sociodemographic 
data and dental/medical records of the families that use the services. Fifteen users were randomly selected from each of the 60 health units (30 FHS and 30 CHC) taking part in the study, giving a total sample of $n=900$. The inclusion criteria specified that users should be over 18 years of age, have been using the oral health services studied for at least 2 years and should not have any mental disorders. The response rate was $100 \%$ once the data collection included home-based interviews and revisiting the homes of participants who were not present at the first visit, at times that were convenient for them.

\section{Data collection}

The data collection instruments used were PCATool-Dentists and PCATool-Users, both of which were adapted for oral health, using the original versions validated for Portuguese. ${ }^{18-21}$ Primary and secondary outcome measures are 'essential' and 'derived' PHC attributes, applied as follows: (a) for users, the essential attributes with their respective number of questions were affiliation (3 questions), first contact/access (3), accessibility (11), continuity of care (14), integration of care (9), information system (3) and comprehensiveness (28). The derived attributes were family orientation (9), cultural competence (8) and community orientation (5). Just to give an example, for the attribute affiliation, the questions are: 'Is there a dentist or oral health service where you usually go when you need advice about your oral health?", 'Is there a dentist or oral health service that knows you best as a person?' and 'Is there a dentist or oral health service that is most responsible for your oral healthcare?'. (b) For dentists, the essential attributes were accessibility (9), continuity of care (12), information system (4) and comprehensiveness (28); and the derived were family orientation (9), community orientation (7) and cultural competence (5). Finally, to summarise in a simple and straightforward way, the essential score and the general score are also calculated for both users and dentists.

When dealing with the instruments, response options were on a 5-point Likert scale: 'definitely yes' (4 points); 'probably yes' (3 points); 'probably no' (2 points); 'definitely no' (1 point) and 'I don't know/I don't want to answer' ( 0 point).

\section{Statistical analysis}

The data were recorded using an Excel spreadsheet and then analysed with Statistica V.7.0 software (Dell, Round Rock, Texas, USA). The scores in the database showed the extent to which the units investigated complied with the principles of PHC. The score was defined based on mathematical calculations and algorithms described in the PCATool Manual. ${ }^{26} \mathrm{~A}$ minimum reference score of 6.6 points was used as the cut-off, corresponding to the minimum performance for an oral health service to satisfy the attributes of PHC. ${ }^{19} 27$ The mean scores for attributes of PHC by users and dentists of FHS and CHC units were evaluated for their distribution pattern using the Lilliefors normality test. All attributes showed a pattern tending to normal distribution; therefore, all tests were parametric.
The single sample t-test was used to assess whether the PHC oral health services achieved the minimum attributes. To compare the attributes and scores for FHS and CHC units for both users and dentists, an independent sample t-test was used; we tested the null hypothesis that the means for the two categories of respondent and two types of health unit were equivalent. The attributes and scores for services operating as part of or outside the FHS were compared with respondents' affiliation using two-factor analysis of variance (ANOVA).

Lastly, the FHS and CHC unit groups, both for users and dentists, were compared using the Fisher's least significant difference (LSD) follow-up test. For this, the post hoc option was chosen under the assumption of a significant $\mathrm{F}$, that is, the null hypothesis of equality of the FHS and CHC units was rejected. Fisher's LSD post hoc (protected) test calculates the SD of all groups combined. Protection means that the calculations were undertaken only when the overall ANOVA resulted in a p value $<0.05$. This stage of data analysis focused on finding patterns and/or relationships between subsets of sampled populations that would otherwise remain undetected. The post hoc analysis limits the likelihood of significant effects being accidentally discovered among the subgroups of a population when such effects do not exist, thereby controlling type I error.

Attributes and scores for users and dentists were compared jointly for each type of health unit. Data provided by the respondents were compared separately in terms of the type of health unit they used and their final scores. A significance level of 0.05 was used for all the analyses.

\section{Patient and public involvement}

In the consent form, which meets the requirements of the Brazilian legislation on human research, participants were informed about the type of study, the main objective, what their involvement and the type of question to be answered, and that they could leave the study to any time and for any reason, without any consequences. The initial disclosure of the research results for the participants has already occurred since workshops were held with managers and dentists of the PHC units. The main results were also presented to the Local Health Councils, which include representatives of local dwellers associations and the organised civil society. Future dissemination will occur through presentations at scientific meetings and through the publication of the manuscript.

\section{RESULTS}

Based on the cut-off point described in the methodological section, with the minimum reference score of 6.6 points, users' perception of major PHC attributes for both FHS or CHC services was favourable $(\geq 6.6)$, except for affiliation and accessibility. Affiliation had a borderline value (6.36) and accessibility was far below the minimum 
Table 1 Mean scores assigned to primary healthcare attributes of oral health services by users of these services in Curitiba, $2011(n=900)$

\begin{tabular}{lllllrc}
\hline Attributes & Mean & SD & SEM & $\mathbf{9 5 \%}$ Cl & t & P value \\
\hline Affiliation & 6.36 & 3.72 & 0.12 & 6.11 to 6.60 & -1.97 & $0.049^{*}$ \\
\hline Access/first contact & 6.78 & 1.54 & 0.05 & 6.68 to 6.88 & 3.57 & $<0.01^{*}$ \\
\hline Accessibility & 5.83 & 0.78 & 0.03 & 5.78 to 5.89 & -29.41 & $<0.01^{*}$ \\
\hline Continuity of care & 7.28 & 0.69 & 0.02 & 7.24 to 7.33 & 29.57 & $<0.01^{*}$ \\
Integration of care & 7.88 & 0.62 & 0.05 & 7.79 to 7.97 & 28.12 & $<0.01^{*}$ \\
Information system & 8.03 & 1.38 & 0.05 & 7.94 to 8.12 & 31.17 & $<0.01^{*}$ \\
\hline Comprehensiveness & 7.15 & 0.71 & 0.02 & 7.10 to 7.20 & 23.19 & $<0.01^{*}$ \\
Clinical comprehensiveness & 7.46 & 0.51 & 0.02 & 7.42 to 7.49 & 50.54 & $<0.01^{*}$ \\
Expanded comprehensiveness & 6.84 & 1.25 & 0.04 & 6.75 to 6.93 & 5.88 & $<0.01^{*}$ \\
Family orientation & 7.22 & 1.15 & 0.04 & 7.15 to 7.30 & 16.21 & $<0.01^{*}$ \\
Cultural competence & 7.58 & 0.92 & 0.03 & 7.52 to 7.64 & 32.20 & $<0.01^{*}$ \\
Community orientation & 7.23 & 1.51 & 0.05 & 7.13 to 7.33 & 12.54 & $<0.01^{*}$ \\
Essential score & 6.93 & 0.86 & 0.03 & 6.88 to 6.99 & 11.62 & $<0.01^{*}$ \\
General score & 7.07 & 0.75 & 0.03 & 7.01 to 7.12 & 18.68 & $<0.01^{*}$ \\
\hline "p
\end{tabular}

${ }^{*} \mathrm{p}<0.05$ indicates statistical significance.

score, with a value of 5.8. In addition to the statistically significant values for these two attributes, the negative results of the t-test were also noteworthy. The attributes assessed by users are shown in table 1 .

The scores ascribed by PHC dentists who worked in FHS and CHC models for comprehensiveness (6.67), expanded comprehensiveness (6.64) and the essential score (6.66) (which includes only the four essential PHC attributes) were borderline. As perceived by the dentists, only the accessibility (5.80) had a mean that was significantly below the expected reference score, again with a negative result for the t-test (table 2).

Regardless of the type of model being analysed, most PHC attributes achieved good mean scores. However, a comparison of the perception of users and dentists associated with FHS (table 3) and that of users and dentists in CHC (table 4) showed that the former had a better perception of the PHC structure and work process.

It is interesting to note that the mean values respectively assigned by users and by dentists in FHS units to the attributes accessibility (5.98 and 5.94) and family orientation (7.96 and 8.07) were nearly equivalent. In contrast, the scores given to the attributes continuity of care (7.61 and 7.11), information system (8.68 and 7.93) and clinical comprehensiveness (7.56 and 6.75) by users were higher than those given by dentists. The mean value of overall score for PHC was 7.53 for users and 7.56 for dentists at FHS, whereas the essential score was statistically higher for users (7.32) than for dentists (7.06), as shown in table 3 .

Table 2 Mean scores assigned to primary healthcare attributes of oral health services by dentists providing these services in Curitiba, $2011(\mathrm{n}=203)$

\begin{tabular}{|c|c|c|c|c|c|c|}
\hline Attributes & Mean & SD & SEM & $95 \% \mathrm{Cl}$ & $\mathbf{t}$ & $P$ value \\
\hline Continuity of care & 6.79 & 0.59 & 0.04 & 6.71 to 6.87 & 4.61 & $<0.01^{*}$ \\
\hline Comprehensiveness & 6.67 & 0.53 & 0.04 & 6.60 to 6.75 & 1.93 & 0.06 \\
\hline Clinical comprehensiveness & 6.70 & 0.33 & 0.02 & 6.66 to 6.75 & 4.49 & $<0.01^{*}$ \\
\hline Family orientation & 7.29 & 0.75 & 0.05 & 7.19 to 7.40 & 13.22 & $<0.01^{*}$ \\
\hline Community orientation & 7.58 & 0.90 & 0.06 & 7.45 to 7.70 & 15.54 & $<0.01^{\star}$ \\
\hline Cultural competence & 7.65 & 1.08 & 0.08 & 7.50 to 7.80 & 13.84 & $<0.01^{\star}$ \\
\hline Essential score & 6.66 & 0.58 & 0.04 & 6.58 to 6.74 & 1.45 & 0.15 \\
\hline
\end{tabular}

${ }^{*} p<0.05$ indicates statistical significance. 
Table 3 Assessment by users and dentists in family health strategy centres of the extent of primary healthcare attributes in oral health services, Curitiba, $2011(n=450 \mathrm{U}, n=79 \mathrm{D})$

\begin{tabular}{|c|c|c|c|c|c|c|c|c|}
\hline \multirow[b]{2}{*}{ Attributes } & \multicolumn{2}{|c|}{ Mean } & \multicolumn{2}{|l|}{ SD } & \multicolumn{2}{|l|}{$95 \% \mathrm{Cl}$} & \multirow[b]{2}{*}{$t$} & \multirow[b]{2}{*}{$P$ value } \\
\hline & U & D & U & D & U & D & & \\
\hline Accessibility & 5.98 & 5.94 & 0.74 & 1.03 & 5.91 to 6.05 & 5.71 to 6.18 & 0.36 & 0.72 \\
\hline Continuity of care & 7.61 & 7.11 & 0.72 & 0.77 & 7.54 to 7.67 & 6.94 to 7.29 & 5.58 & $<0.01^{*}$ \\
\hline Information system & 8.68 & 7.93 & 1.26 & 1.47 & 8.56 to 8.80 & 7.60 to 8.26 & 4.73 & $<0.01^{*}$ \\
\hline Comprehensiveness & 7.55 & 7.23 & 0.45 & 0.22 & 7.51 to 7.59 & 7.18 to 7.29 & 6.07 & $<0.01^{*}$ \\
\hline Clinical comprehensiveness & 7.56 & 6.75 & 0.44 & 0.42 & 7.52 to 7.60 & 7.30 to 7.40 & 15.36 & $<0.01^{*}$ \\
\hline Expanded comprehensiveness & 7.53 & 7.72 & 0.82 & 0.42 & 7.46 to 7.61 & 6.04 to 6.27 & 2.06 & $0.04^{*}$ \\
\hline Family orientation & 7.96 & 8.07 & 1.04 & 0.35 & 7.86 to 8.06 & 7.99 to 8.15 & -0.95 & 0.34 \\
\hline Cultural competence & 8.08 & 8.42 & 0.90 & 0.43 & 7.99 to 8.16 & 8.33 to 8.52 & -3.32 & $<0.01^{*}$ \\
\hline Community orientation & 7.78 & 8.19 & 1.16 & 0.72 & 7.68 to 7.89 & 8.03 to 8.35 & -3.00 & $<0.01^{*}$ \\
\hline Essential score & 7.32 & 7.06 & 0.65 & 0.55 & 7.26 to 7.38 & 6.92 to 7.20 & 3.48 & $<0.01^{*}$ \\
\hline General score & 7.53 & 7.56 & 0.50 & 0.35 & 7.48 to 7.58 & 7.45 to 7.67 & -0.55 & 0.58 \\
\hline
\end{tabular}

${ }^{*} \mathrm{p}<0.05$ indicates statistical significance.

$\mathrm{D}$, dentists; U, users.

Analysis of users' and dentists' perception of oral health services in CHC revealed statistically significant differences for some of the attributes analysed. Respectively, users assigned higher mean values than did dentists to the essential attributes continuity of care (6.96 and 6.59), information system (7.39 and 7.02), comprehensiveness (6.75 and 6.31) and clinical comprehensiveness (7.35 and 6.68). In contrast, the attributes family orientation (6.49 and 6.80) and community orientation (6.68 and 7.19) had significantly lower mean values when assessed by users than when assessed by dentists, respectively. The attributes accessibility, expanded comprehensiveness and cultural competence were equivalent for users and dentists (table 4).
The assessments of essential score (6.54 and 6.41) and overall score (6.61 and 6.68) were nearly equivalent for users and dentists in CHC, respectively (table 4). When responses for users in units associated with the FHS and those with CHC were compared, better results for all attributes were observed for oral health services implemented in the FHS, as shown in figure 1.

\section{DISCUSSION}

This study showed that summary measures such as essential and general scores indicate that the oral health services investigated are generally compatible with the attributes

Table 4 Assessment by users and dentists in conventional healthcare of the extent of primary healthcare attributes in oral health services, Curitiba, 2011 ( $n=450 \mathrm{U}, \mathrm{n}=124 \mathrm{D})$

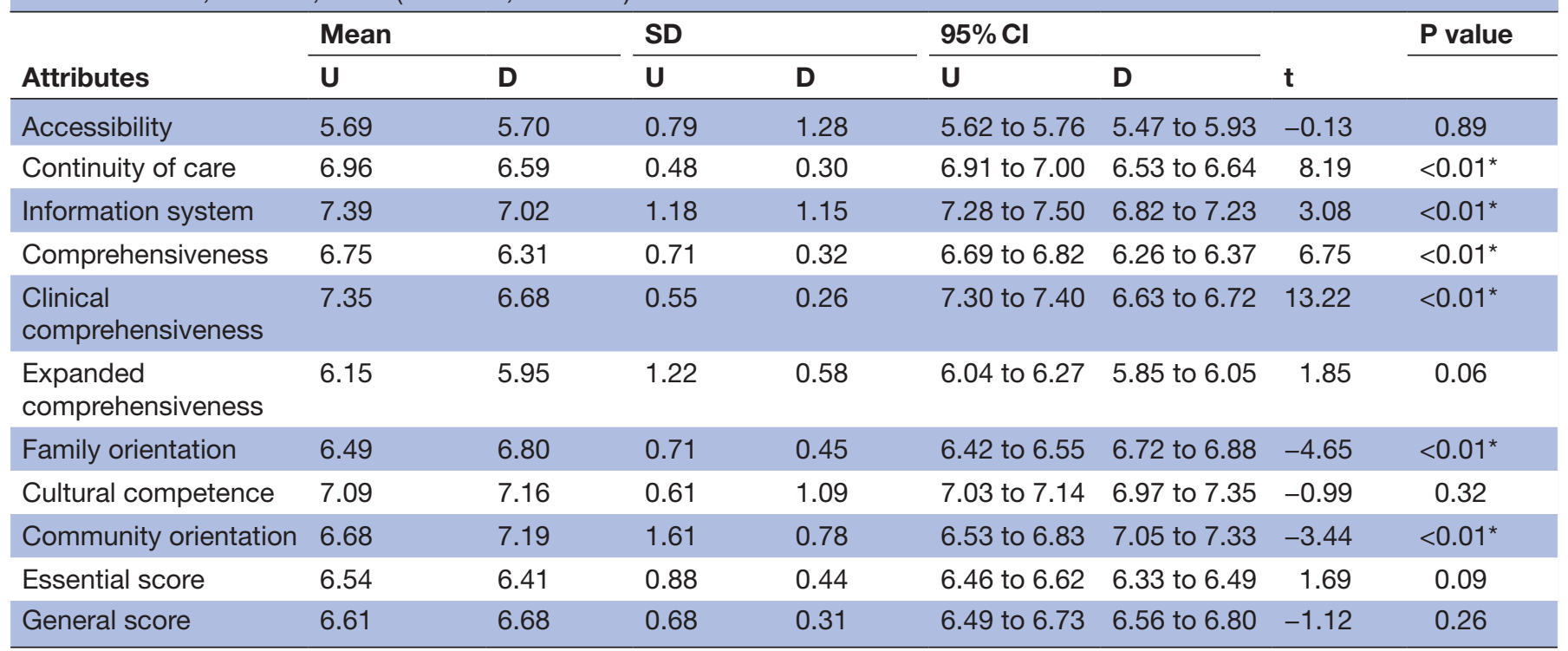

${ }^{*} \mathrm{p}<0.05$ indicates statistical significance.

$\mathrm{D}$, dentists; U, users. 
Current effect size: $F(10,12111)=60.974 ; p=0.0000 ; \eta^{2}=0.08$

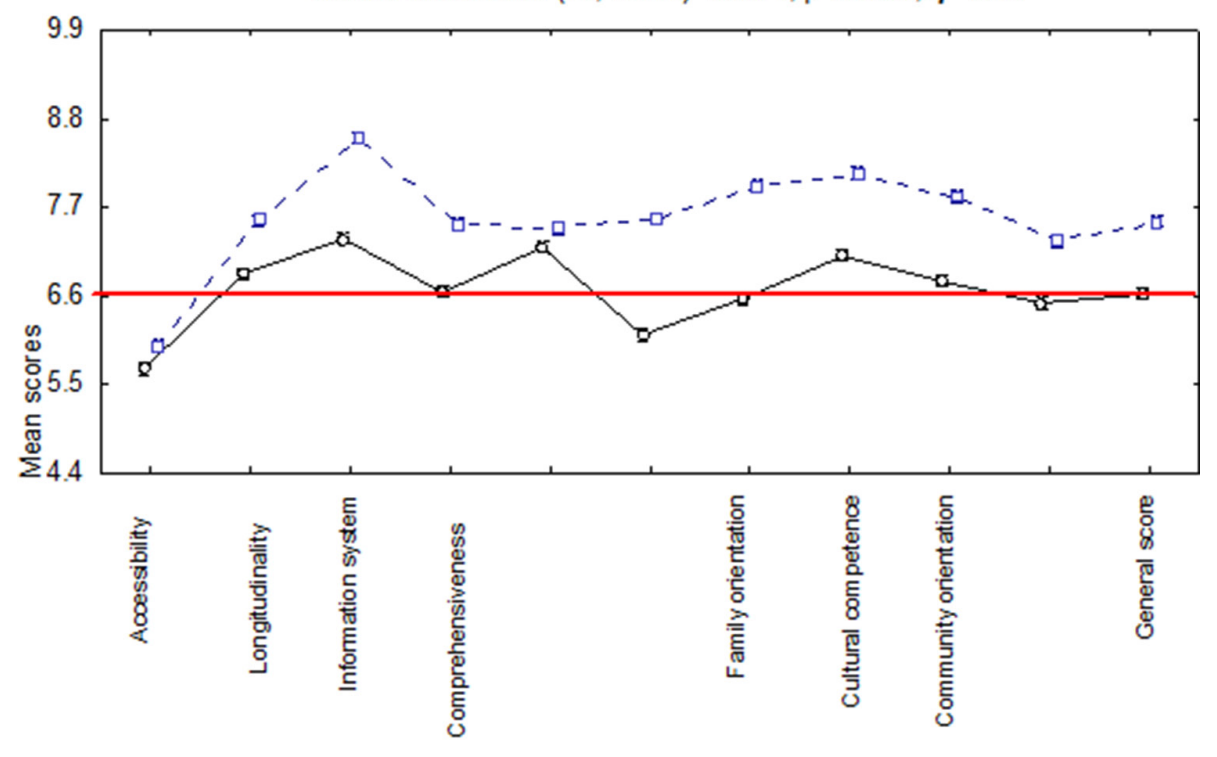

들 Conventional Health Care (CHC)
두. Family Health Strategy (FHS)

Figure 1 Comparative assessment of primary healthcare attributes in family health strategy and conventional healthcare services for the users category of study participants, Curitiba, 2011.

of good PHC. However, there is a need for changes to be made in the work process of PHC dental services. This is particularly evident in the scores for some essential PHC attributes, such as affiliation and accessibility, in which improvement must be emphasised.

It is paradoxical that the FHS was introduced in Curitiba to improve access to health services but it has proved ineffective in guaranteeing this right in the case of dental services. Inadequate access to a dentist conflicts with the Brazilian Constitution of the Federative Republic of Brazil, which states that health is a universal right, ${ }^{13}$ a controversial issue at a time of economic crisis in various countries but the goal of historic struggles in Brazilian society.

Affiliation denotes the quality of patient follow-up. This attribute assesses whether there a professional present who is responsible for serving patients or whether there is a health service available that is tailored for them when they are sick or need health advice. Similarly, there are several reasons for barriers of access to oral health services and utilisation rates, such as a sufficient supply of services and geographical, cultural and functional accessibility. Sociodemographic factors, scheduling services to meet adult workers' needs, distance to the healthcare facility, perceived needs, as well as personal beliefs and an emphasis on oral health are influences to be considered in the discussion of accessibility. ${ }^{10} 28$

For the continuity of care, the dentists who participated in the study seem to not treat users based merely on their complaints during a consultation but consider them as a whole and seek to follow patients over time, a desirable condition for oral health. The coordination/integration of care and coordination/access to the information system indicate that the services control access to specialised services. There is an institutional regulation preventing users from seeking these services directly and requiring them to be seen in the PHC units first. We also found that PHC users and dentists have satisfactory access to patients' dental/medical records, which is important for the maintenance of oral health and follow-up of any procedures carried out.

The comprehensiveness attribute was evaluated positively by dentists and users. A comprehensive list of services or guidelines that people may need at some point includes promotion, prevention, cure and rehabilitation. Some services may not be offered within the PHC units but patients are referred to specialists and hospitals instead. Comprehensiveness is central to the guidelines of the SUS and should be on the agendas of public health managers and dentists as they seek to build a more equitable society by providing integral services for all. ${ }^{19} 29$ The greater extent of this attribute in FHS shows that public health managers and oral health teams are progressively adopting the social determinants of health model, which is part of a set of public policies that seek to reduce health inequalities in many countries. ${ }^{730} 31$

The overall performance of the FHS and CHC in terms of derived PHC attributes (family orientation, cultural competence and community orientation) was assessed positively by users and dentists. This indicates support for oral health policies that endeavour to develop inclusive and contextualised health services at the local level. If these attributes are satisfied, there is greater potential for users to establish links with and have confidence in PHC teams. This finding contrasts with the results of Lewis $e t a l,{ }^{29}$ who found that people do not attach much 
importance to PHC services, preferring instead the services of specialists because of their perceived greater ability to solve patients' problems.

The finding that FHS units were assessed better than CHC by users and dentists lends support to the municipal government's decision to implement the FHS in 1994, with a view to providing a new basis for the work of dental teams and a positive new focus on the oral healthcare model.

The study has strengths and limitations. It uses an instrument validated internationally and with cross-cultural validation for Portuguese. In this research, we worked with PCATool in a scenario of primary care services that includes oral health. Therefore, we did an innovative study applying the PCATool in the context of oral health. Because it is a cross-sectional study, the limitations include the difficulty in establishing causal relationships. The tool is based on reports of subjective self-perception about primary care services rather than clinical observation; therefore, the outcomes do not allow a direct measurement of the possible benefits in clinical terms. In addition, research addressing the degree of patient satisfaction often reports good levels of satisfaction with the available health system, even when the observed quality is very low. This does not appear to be the case as the scores obtained from the patients were not disproportionately different from those given by the dentists. Additionally, both groups agreed to assign a low score to the accessibility attribute. It has to be emphasised the research findings that placed the FHS scores always higher than the CHC model, revealing consistency in the responses of the two groups of respondents.

By identifying the presence and extent of PHC attributes in oral health services, this study can be expected to help researchers, public health managers and dental teams to improve oral health services.

\section{CONCLUSIONS}

The results reveal a reasonable level of attainment of PHC attributes in the services investigated. Nevertheless, public health managers should make efforts to reduce the difficulties faced by users in accessing dental care. The more positive results achieved by FHS services indicate that the provision of oral healthcare under this strategy should be expanded.

Contributors ACN conceived the study, conducted the acquisition of data and approved the final version to be published. STM helped design and interpret the study, revised the manuscript critically for important intellectual content and approved the final version to be published. RIW analysed and interpreted the data, drafted the work and approved the final version to be published. SJM conceived the study, revised the manuscript critically and approved the final version to be published. MCLG drafted the work, revised the manuscript critically and approved the final version to be published.

Funding The authors have not declared a specific grant for this research from any funding agency in the public, commercial or not-for-profit sectors.

Competing interests None declared.

Patient consent for publication Not required.
Ethics approval This study was approved by the Research Ethics Committee at the Pontifícia Universidade Católica do Paraná (prot. no. 3646/09).

Provenance and peer review Not commissioned; externally peer reviewed.

Data sharing statement There are no additional unpublished data from the study.

Open access This is an open access article distributed in accordance with the Creative Commons Attribution Non Commercial (CC BY-NC 4.0) license, which permits others to distribute, remix, adapt, build upon this work non-commercially, and license their derivative works on different terms, provided the original work is properly cited, appropriate credit is given, any changes made indicated, and the use is non-commercial. See: http://creativecommons.org/licenses/by-nc/4.0/.

\section{REFERENCES}

1. Rasella D, Aquino R, Santos CA, et al. Effect of a conditional cash transfer programme on childhood mortality: a nationwide analysis of Brazilian municipalities. Lancet 2013;382:57-64.

2. World Health Organization. Declaration of alma-ata. 12. Alma-Ata, USSR, 6-12: International Conference on Primary Health Care, 1978.

3. Starfield B. Primary care: balancing health needs, services and technology. New York: Oxford University Press, 1998.

4. Macinko J, Marinho de Souza MF, Guanais FC, et al. Going to scale with community-based primary care: an analysis of the family health program and infant mortality in Brazil, 1999-2004. Soc Sci Med 2007;65:2070-80.

5. Rasella D, Aquino R, Barreto ML. Reducing childhood mortality from diarrhea and lower respiratory tract infections in Brazil. Pediatrics 2010;126:e534-e540.

6. Nesbitt RC, Lohela TJ, Soremekun S, et al. The influence of distance and quality of care on place of delivery in rural Ghana. Sci Rep 2016;6:30291.

7. Nascimento AC, Moysés ST, Bisinelli JC, et al. Oral health in the family health strategy: a change of practices or semantics diversionism. Rev Saude Publica 2009;43:455-62.

8. Ministry of Health of Brazil. National survey of oral health. Main results. Brasília: Ministry of Health, 2012.

9. Leake JL, Birch S. Public policy and the market for dental services. Community Dent Oral Epidemiol 2008;36:287-95.

10. Garcha V, Shetiya SH, Kakodkar P. Barriers to oral health care amongst different social classes in India. Community Dent Health 2010;27:158-62.

11. Willie-Stephens J, Kruger E, Tennant M. Public and private dental services in NSW: a geographic information system analysis of access to care for 7 million Australians. N S W Public Health Bull 2014;24:164-70.

12. Listl S. Countries with public dental care coverage have lower social inequalities in the use of dental services than countries without such coverage. J Evid Based Dent Pract 2015;15:41-2.

13. BrasilFederal Senate. Constituição da República Federativa do Brasil. Brasília: Federal Senate, 1998.

14. Nascimento AC, Moysés ST, Werneck RI, et al. Oral health in the context of primary care in Brazil. Int Dent J 2013;94:n/a-43.

15. Williams DM, Medina J, Wright $D$, et al. A review of effective methods of delivery of care: skill-mix and service transfer to primary care settings. Prim Dent Care 2010;17:53-60.

16. Alencar MN, Coimbra LC, Morais AP, et al. [Evaluation of the family focus and community orientation in the family health strategy]. Cien Saude Colet 2014;19:353-64.

17. Cassady CE, Starfield B, Hurtado MP, et al. Measuring consumer experiences with primary care. Pediatrics 2000;105:998-1003.

18. Harzheim E, Starfield B, Rajmil L, et al. [Internal consistency and reliability of Primary Care Assessment Tool (PCATool-Brasil) for child health services]. Cad Saude Publica 2006;22:1649-59.

19. Almeida C, Macinko J. Validation of methodology of quick evaluation of the organizational and performance characteristics of the basic health services of the health system (SUS) at local level. Brasilia: Pan American Health Organization / Ministry of Health 2006.

20. Harzheim E, de Oliveira MMC, Agostinho MR, et al. Validation of the Primary Care Assessment Tool: PCATool-Brazil for adults. Rev Bras Med Fam Comunidade 2013;8:274-84.

21. Hauser L, Castro RCL, Vigo A, et al. Translation, adaptation, validity and reliability of the Instrument for Assessment of Primary Health Care (PCAToll) in Brazil: version for health professionals. Rev Bras Med Fam Comunidade 2013;8:244-55.

22. Shi L, Starfield B, Xu J. Validating the adult primary care assessment tool. J Fam Prac 2001;50:161-75.

23. Atchison KA, Weintraub JA, Rozier RG. Bridging the dental-medical divide: Case studies integrating oral health care and primary health care. J Am Dent Assoc 2018;149. 
24. Harnagea $\mathrm{H}$, Lamothe L, Couturier $\mathrm{Y}$, et al. From theoretical concepts to policies and applied programmes: the landscape of integration of oral health in primary care. BMC Oral Health 2018;18:23.

25. Appleby J. Dentistry: should it be in the NHS at all? BMJ 2016;355:i5986.

26. Municipal Secretary of Health. Network of oral health care. Curitiba: Municipal Secretary of Health, 2016.

27. Ministry of Health. Ministry of Health of Brazil. Primary Care Assessment Tool (PCATool-Brasil). Brasília, 2018.
28. Pan American Health Organization. Renewing primary health care in the americas: a position paper of the pan American Health Organization/World Health Organization (PAHO/WHO). Geneva: Pan American Health Organization, 2018

29. Lewis M, Eskeland G, Traa-Valerezo X. Primary health care in practice: is it effective? Health Policy 2004;70:303-25.

30. Watt RG. Social determinants of oral health inequalities: implications for action. Community Dent Oral Epidemiol 2012;40:44-8.

31. Williams DM, Sheiham A, Watt RG. Oral health professionals and social determinants. Br Dent J 2013;214:427. 